\title{
Antiliberales en el escaño durante las Cortes de Cádiz (1810-1813)
}

\author{
María del Mar Alarcón Alarcón 1 \\ Universidad de Alicante \\ mar.alarcon@ua.es
}

RESUMEN: En este artículo se examinan, principalmente a través de los Diarios de Sesiones, las posiciones políticas defendidas por algunos diputados antiliberales en las Cortes Generales y Extraordinarias (1810-1813). Las Cortes, que fueron el órgano de poder preponderante en el territorio español que escapaba al control de las autoridades bonapartistas, se configuraron como un espacio de debate y decisión, lo cual supuso una ruptura con las concepciones politicas existentes durante el Antiguo Régimen, entre ellas, la absolutista. Los sectores sociales antiliberales más conservadores y reaccionarios utilizaron diversos mecanismos y cauces (la propaganda, el ejército, el púlpito, los cargos municipales, la diplomacia, las elecciones a Cortes, etc.) para acabar con ese nuevo espacio. Pese a su incidencia sobre la formación y evolución de la sociedad y del Estado en la España contemporánea, la historiografía ha prestado poca atención a la génesis y bases sociales de la contrarrevolución antiliberal. No abundan los estudios acerca de los orígenes y organización de dicho fenómeno histórico, como tampoco de las ideas y actitudes de los diputados opuestos al constitucionalismo gaditano. Consideramos que estas lagunas en el conocimiento justifican la pertinencia del presente trabajo, en el que se intenta una primera aproximación al tema.

\section{Palabras clave: Cortes de Cádiz; Contrarrevolución; Diputados an- tiliberales; Guerra de la Independencia española.}

\section{The anti-liberal deputies in the Cortes of Cadiz (1810-1813)}

ABSTRACT: This article attempts to analyze, mainly drawing on the Parliamentary Debates, the political positions adopted by some anti-liberal deputies in the Cortes of Cadiz. This representative chamber (which was the leading

1 ORCID iD: http//orcid.org/0000-0003-0920-5232. 
organ of political power in the Spanish lands not controlled by the Bonapartist regime) was set up as a discussion and decision-making space, which entailed a rupture with conceptions of politics prevailing during the Ancien Régime, including Absolutism. The more conservative and reactionary groups used several mechanisms and ways (the propaganda machine, army, pulpit, municipal posts, diplomacy and Parliamentary elections, among others) to put an end to that new place. Despite of its impact on the making and development of Society and State in Contemporary Spain, historians have paid little attention to the genesis and social bases of the Counter-Revolution. A small number of studies are focused on the origins of this historical movement, as well as on the various ideas and political attitudes of the deputies opposed to the constitutional regime of 1812. These gaps in knowledge have motivated the present pages. Our aim is to offer a first approach to the question.

KEY WORDS: Cortes of Cadiz; Counter-Revolution; Anti-liberal deputies; Peninsular War.

CÓMO CITAR ESTE ARTÍCULO/CITATION: Alarcón Alarcón, María del Mar, «Antiliberales en el esacaño durante las Cortes de Cádiz (1810-1813)», Hispania, 77/256 (Madrid, 2017): 349-374. doi: 103989/hispania.2017.010.

\section{SOBRE LOS ORÍGENES DEL ANTILIBERALISMO ESPAÑOL}

El nacimiento de la revolución liberal en España hay que ponerlo en relación con la propagación de las ideas ilustradas, la crisis de legitimidad de la monarquía absoluta y el estallido de la Guerra de la Independencia. Los historiadores han aplicado varias categorías analíticas para referirse a las múltiples formas de oposición a la revolución liberal. Entre estos conceptos, se mencionarán los de «contrarrevolución antiliberal», «realismo»y «antiliberalismo reaccionario» ${ }^{2}$. En estas páginas se entiende por contrarrevolución un movimiento social y político, de carácter interclasista, que surge en el territorio controlado por las Cortes de Cádiz a partir de 1810 con el fin de impedir la consolidación de un Estado liberal en España ${ }^{3}$. Conviene subrayar que dentro del grupo antiliberal activo en la cámara entre 1810 y 1813 coexistieron varias tendencias y actitudes políticas (reformistas, conservadoras y reaccionarias) que conectaban con grupos y personas con intereses diversos, en ocasio-

2 ARÓSTEGUI, 1990, vol. II: 573-594 (quien no trata en este trabajo el período de las Cortes de Cádiz). LUIS, 2014. RÚJULA, 2014, vol. II: 377-410. Entre los términos utilizados por los historiadores para designar a los partidarios del Antiguo Régimen, se encuentran los de «serviles», «reaccionarios» y «absolutistas».

3 Sobre la crítica del concepto de contrarrevolución: HALÉVI, 1990: 29-32. MARTIN, 1996: $140-141$. 
nes enfrentados. Así, por ejemplo, los diputados antiliberales defendieron opiniones distintas a propósito de cuestiones tan importantes como los límites del poder del rey, la organización y atribuciones de las Cortes, los niveles de centralización administrativa y uniformización jurídica de la monarquía española, la promoción de la nueva nobleza de mérito o la conveniencia de modificar el antiguo sistema impositivo ${ }^{4}$. La hostilidad y el miedo a la revolución, que no cesaron de aumentar a medida que las Cortes desarrollaban su labor legislativa y los josefinos perdían importantes plazas militares (como es sabido, la guerra cambió de signo en el verano de 1812), influyeron decisivamente en el hecho de que los sectores sociales antiliberales acabaran convergiendo en un frente común, en modo alguno homogéneo, bajo el lema de «religión, patria y rey», ya enarbolado, aunque con otras miras, durante la Guerra contra la Convención francesa, y en 1808 por quienes se levantaron en armas contra Napoleón ${ }^{5}$.

En un primer momento, los antiliberales o contrarrevolucionarios, como prefiramos denominarlos, adoptaron posiciones divergentes sobre las medidas políticas que convenía adoptar para resolver la crisis política de 1808. Eso sí, todos ellos se opusieron a que se cuestionaran los principios básicos sobre los que se asentaban la sociedad y el régimen político hasta entonces vigentes. Fue frecuente el recurso a las viejas metáforas orgánica y familiar para fundamentar el papel preponderante del rey en el terreno político y la estructura jerárquica de la sociedad tradicional ${ }^{6}$. Este grupo compartía una concepción estamental de la sociedad: sus ideas del rey, de la soberanía, de la nación y de las Cortes eran coherentes con ella.

En un intento por apropiarse del mito del rey deseado, los antiliberales se aplicaron a sí mismos el apelativo de «realistas», presentándose como los verdaderos valedores de Fernando VII, cuya persona era uno de los símbolos de la España antibonapartista 7 . Y, sin embargo, en 1810 muchos se pronunciaron a favor de la adopción de medidas urgentes para impedir que en un futuro la monarquía volviera a dar paso al «despotismo» y la «tiranía» de los últimos reinados (con la excepción, claro está, del de Fernando VII). Cierta-

4 Los diputados Ramón Lázaro de Dou y José Duaso y Latre, sacerdote aragonés, por ejemplo, tenían distintos pareceres sobre la conveniencia de establecer la contribución directa. Diario de Sesiones de las Cortes generales y extraordinarias (DSCGE), 816 (19/07/1813): 5749 (ed. 1870). DUASO (DUAZO) Y LATRE, 1814.

5 ROURA, 2001: 205-220. RUJULA, 86/2 (Madrid, 2012): 46.

6 Acerca del uso de las metáforas orgánica y familiar en la España de 1808, véase: HOCQUELLET, 2010: 51-66. Sobre el papel moderador del rey en la corte del Antiguo Régimen: DEDIEU, 2005.

7 Sobre la construcción de la imagen de Fernando VII y los orígenes del mito del rey deseado: LA PARRA LÓPEZ, 2007. Los antiliberales identificaron «liberalismo» con «republicanismo», «democracia» y «Revolución francesa». FERNÁNDEZ SEBASTIÁN, 134 (Madrid, 2006): 136 y ss. 
mente, no era la primera vez que se empleaban estos conceptos e ideas. A lo largo del siglo XVIII por la corte y las provincias habían cundido comentarios negativos sobre la potenciación de las secretarías del Despacho, la política patrimonialista impulsada desde las mismas y los servidores nombrados por el rey para ponerla en práctica ${ }^{8}$. En concreto, durante el reinado de Carlos IV una parte significativa del clero y las viejas familias de la aristocracia, en unión de otros sectores sociales, presionaron sobre el monarca para paralizar las medidas que perseguían la ampliación del poder de la Corona y el aumento de los ingresos de la Real Hacienda, las cuales lesionaban sus intereses e influencia social. En nombre de unas supuestas leyes fundamentales de la monarquía, los descontentos con el «mal gobierno» (expresión ésta muy utilizada en pasquines, panfletos y otros escritos de circunstancias), clamaron, primero, contra el «despotismo ministerial» (el secretario del Despacho de Hacienda fue muy criticado), y a partir de 1801, contra el «despotismo» y la «tiranía» del generalísimo Manuel Godoy. Dichos sectores acabaron por agruparse en torno al príncipe de Asturias, futuro sucesor al trono, cuya imagen estaba fuertemente asociada a la de restaurador de las leyes fundamentales de la monarquía. La Conspiración de El Escorial y el Motín de Aranjuez fueron dos intentos conocidos, uno frustrado y otro exitoso respectivamente, para derribar al hombre de confianza del rey absoluto9.

Entre los meses de mayo y junio de 1808 una parte de la población española, encabezada por las juntas locales y provinciales, negó la validez de los tratados suscritos entre la familia real y Napoleón en Bayona, movilizándose militarmente en defensa de Fernando VII. Insistimos en que este monarca había subido al trono en marzo de 1808 mediante un golpe de Estado respaldado, entre otros, por sectores contrarios a la política patrimonialista de la Corona, a la que algunos estudiosos se han referido con el nombre de «reformismo borbónico» ${ }^{10}$. Con anterioridad a esta fecha, algunas personas socialmente muy influyentes se habían atrevido a cuestionar sin ambages la potestad absoluta de los monarcas españoles. Especial atención merece José Ignacio de Joven, abogado del duque del Infantado, Pedro Alcántara de Toledo y Salm-Salm, quien en una alegación presentada ante el Consejo de Hacienda, que fue dada a la imprenta en 1804, solicitaba la anulación de la demanda de incorporación a la Corona de la baronía de Alberique aduciendo, entre otras, estas razones:

8 GARCÍA MONERRIS, 2004: 60-90; 363-381.

9 LA PARRA LÓPEZ, 2005: 232-252; 348-397. Durante el reinado de Carlos III, los «arandistas» habían censurado el «despotismo ministerial» de Floridablanca. OLAECHEA, 1969: 53-54; 115.

10 Sobre la crítica de los conceptos historiográficos «reformismo borbónico» y «despotismo ilustrado»: SÁNCHEZ BLANCO, 2002. 
Todos saben que el señor rey don Jaime I de Aragón resolvió, emprendió y verificó en la mayor parte la gloriosa conquista del Reyno de Valencia; pero muchos ignoran los pactos y obligaciones con que se acordó e hizo dicha conquista, la conformidad de estos pactos con las leyes fundamentales de aquel reyno conquistador, y lo que según estas leyes y pactos adquirió el rey y su real Corona en virtud de dicha conquista, ignorándose estas cosas por no fixar la atención sobre la constitución y estado que tenía en aquel tiempo la monarquía de Aragón, y equivocándolo con el que fue recibiendo en los siglos posteriores y tiene al presente. Esta inadvertencia y falta de crítica hizo concebir a algunos escritores la idea de que los señores reyes conquistadores en el principio fueron propietarios y dueños absolutos de todas las tierras que se conquistaban de los moros; pero la ilustración de los señores fiscales no puede dudar que esta opinión se halla resistida por las mismas leyes y desacreditada por las historias del reyno ${ }^{11}$.

En otro contexto histórico (el de la Guerra de la Independencia) y desde una posición bien alejada de la que acaba de referirse, algunos de los antiguos servidores de Carlos IV arremetieron también contra la orientación política dada a la monarquía en las últimas décadas del siglo. Es el caso de Jovellanos, enemigo de Godoy, quien en su Consulta de la convocación de las Cortes, firmada en Sevilla en 21 de mayo de 1809, sostuvo que el poder de los monarcas españoles no era absoluto y que correspondía a las Cortes tradicionales restablecer la Constitución española «después de veinte años de escandaloso despotismo» ${ }^{12}$. Dos años después, este parecer fue suscrito, aunque de forma anónima, por un destacado antiliberal: el marqués de Villaverde, empeñado en demostrar la ilegitimidad de las Cortes de Cádiz y la invalidez del proyecto de Constitución presentado a las mismas el 25 de agosto de 1811, así como en propagar los argumentos aducidos por los diputados afines a sus convicciones políticas ${ }^{13}$.

11 JOVEN y TOLEDO Y SALM-SALM, 1804: 3r-3v. Este documento está firmado en Madrid el 29 de febrero de 1804. Actualmente, custodian ejemplares del impreso, entre otras instituciones: la Biblioteca del Congreso de los Diputados (Madrid), la Biblioteca Nacional de España, la Biblioteca Pública de Burgos, la Biblioteca Pública de Castilla-La Mancha (Toledo), la Biblioteca Pública de Palma de Mallorca y la Biblioteca Pública del Estado de Orihuela.

12 JOVELLANOS, 1811: 105.

13 «Concluyen las reflexiones generales sobre el plan de la Constitución», El Sensato (Santiago de Compostela), 21 de mayo de 1812. El marqués de Villaverde reconoció la autoría de sus escritos periodísticos tras el golpe de Estado de 1814: VILLAVERDE, 1814: 5. En 1812, Villaverde, que había sido miembro de la Junta de Orense, decía: «Nuestros reyes, en medio del despotismo a que es preciso convenir llegaron los últimos, tuvieron siempre una barrera poderosa en nuestras leyes, usos y costumbres, en la opinión pública que de estos elementos resultaba, y en el amor de sus pueblos». El Sensato (Santiago de Compostela), 6-21812. El aristócrata matizó estas afirmaciones tras el regreso de Fernando VII en 1814: «Nuestros reyes, en medio del despotismo a que se dice haber llegado los últimos, tuvieron siempre una barrera poderosa en nuestras leyes, usos y costumbres, en la opinión pública que 
Durante el verano de 1809, con motivo de la llamada Consulta al país, individuos reputados por su conservadurismo habían firmado o auspiciado la impresión de escritos en los que se censuraba la forma en la que los monarcas españoles habían ejercido el poder a lo largo de los siglos, con especial insistencia en los reinados de Carlos III y Carlos IV. Muchos de ellos afirmaron que la vulneración de las leyes fundamentales de la monarquía por parte de los validos, ministros y hombres de confianza de los reyes (sobre todo Godoy), junto con la ejecución de reformas perjudiciales para la Iglesia y la alta nobleza, eran las principales causas de la pérdida de la hegemonía de la monarquía hispánica en Europa ${ }^{14}$. Desde estos postulados, las abdicaciones de Bayona y el posterior estallido de la guerra eran vistos como el desenlace previsible y trágico de la larga decadencia de España, sellada por la perfidia de Napoleón. Por estas fechas, fray Tomás de Salas, de la Orden de los Mínimos y capellán del duque del Infantado, mantenía que la crisis política de la monarquía se resolvía:

[...] con soberano del todo dependiente de la ley, con un Consejo [de Castilla] bastante autorizado para oponerse a su transgresión, sostener su fuerza, explicar su espíritu y resistir a la privada voluntad del rey, con una representación nacional junta de tiempo en tiempo, con el nombre de Cortes con facultades ilimitadas para crear leyes conforme a los intereses de las diversas provincias ${ }^{15}$.

Los diputados antiliberales hablaron de la necesidad de acometer la reforma de un antiguo cuerpo de leyes fundamentales españolas como condición imprescindible para restaurar la forma de gobierno legítima en España, que no era otra que la «monarquía moderada» ${ }^{16}$. Sin embargo, no hubo unanimidad entre ellos respecto a las decisiones políticas que convenía adoptar para limitar (en la época se utilizaron con frecuencia los términos «moderar» y «templar») las atribuciones del monarca, ni sobre el contenido del tantas veces invocado código de leyes de la monarquía. El diputado por Asturias Pedro Inguanzo, en una de sus intervenciones con motivo de la discusión del proyecto constitucional, opinó que para «impedir que la monarquía degenere en un poder absoluto y arbitrario» había que asegurar la reunión periódica de Cortes, ya que éstas eran «sin duda el contrapeso que puede tener la autoridad real para moderar su poder». Y a continuación, dijo que las Cortes eran «una

de estos elementos resultaba, y en el amor de sus pueblos». Op. cit.: 15. La cursiva es nuestra. Sobre el debate del proyecto constitucional: MARTÍNEZ PÉREZ, 2011.

14 REGUERA VALDELOMAR, 1810.

15 SALAS, 1809. La cursiva es nuestra.

16 El diputado Alonso María de Vera y Pantoja, por ejemplo, empleó la expresión «monarquía moderada» para referirse a la antigua forma de la monarquía española. DSCGE, 452 (29/12/1811): 2488. 
de las partes esenciales de la antigua Constitución de España, una de sus leyes fundamentales, el mayor, el único recurso que tiene la nación para conservar sus derechos» ${ }^{17}$. Cabe observar que este diputado se situaba en el sector más inmovilista dentro del espectro antiliberal. Su posición en relación a este asunto entronca con la de otros individuos que con anterioridad al 24 de septiembre de 1810 habían defendido que los reyes estaban llamados de manera ineludible por la antigua constitución a escuchar al reino congregado en Cortes. Francisco Javier Borrull y Vilanova, en su Discurso sobre la Constitución que dio al reyno de Valencia su invicto conquistador el señor don Jayme Primero (1810), que firmó como juez de diezmos, primicias y terciosdiezmos y no como diputado, sostuvo que correspondía a las Cortes autorizar la aprobación de nuevas leyes y tributos ${ }^{18}$. Pero lo cierto es que los diputados antiliberales acabaron utilizando el mito de la antigua constitución de la monarquía española para contener la labor legislativa de las Cortes generales y extraordinarias. Los argumentos de los antiliberales y su diagnóstico de las causas de la crisis de 1808 cambiaron a lo largo de la guerra.

Los contrarrevolucionarios se pronunciaron a favor de las Cortes estamentales y rechazaron en bloque las propuestas de dotar a las Cortes de una estructura unicameral permanente. Todos negaron el principio de igualdad jurídica de los ciudadanos ante la ley. Entre ellos, hubo quienes se decantaron por el bicameralismo de inspiración inglesa (Inguanzo, Cañedo y Vigil), lo cual suponía, por cierto, una innovación en el ordenamiento institucional; otros se inclinaron por el mantenimiento de la organización tradicional (Ostolaza) ${ }^{19}$. Cabe anotar que lord Holland y John Allen habían ponderado las ventajas del bicameralismo en un escrito titulado Suggestions on the Cortes (Londres, Blackader Printer, 1809), que también se imprimió en castellano con el título de Insinuaciones sobre las Cortes $^{20}$. Ambos autores, que partían de la base de que «el clero y la nobleza deben conservar su separada representación», consideraban que «dos cámaras o salas dan tiempo a la reflexión y oportunidad para consultar la opinión pública, antes que las propuestas hechas en el cuer-

17 DSCGE, 345 (12/09/1811): 1822. Sobre Inguanzo: RODRÍGUEZ LÓPEZ-BREA, 71 (2013): 77-91.

18 BORRULL Y VILANOVA, 1810: 8. Entre 1789 y 1791, los «aristocrates» franceses se pronunciaron a favor de la restauración de una constitución histórica de la monarquía y contra el «despotisme». SAINT VICTOR, 2010: 8-36.

19 DSCGE, 345 (12/09/1811): 1826. Véase: FRIERA ÁLVAREZ, 14 (2013): 1-43. PORTILLO VALDÉS, 1998; 545-585. Con anterioridad, Jovellanos se había pronunciado a favor del establecimiento de unas Cortes bicamerales, al estilo británico: BARAS ESCOLÁ, 1993. CORONAS GONZÁLEZ, 1 (2000): 63-96. La idea de Cortes estamentales fue descartada definitivamente en la sesión de 13 de septiembre de 1811 por 112 votos contra 31.

20 En la Biblioteca Nacional de España se conserva un ejemplar del impreso que contiene la traducción al español del texto de Holland y Allen: BNE, U/10517(2). 
po legislativo lleguen a establecerse como leyes» ${ }^{21}$. En la propagación de este influyente papel se empleó a fondo el duque del Infantado, amigo de Holland y enemigo de Jovellanos 22 .

Tras el golpe de Estado perpetrado en mayo de 1814, el duque de Montemar, destacado antiliberal, emitió un dictamen en el que abogaba por la convocatoria de Cortes por estamentos. En aquellas circunstancias políticas, tan distintas de las de 1809, le parecía al aristócrata que las Cortes:

[...] deben ser compuestas por clases, o bien siguiendo el método de las dos cámaras del parlamento inglés, que propone el lord Holland en su papel escrito en castellano e impreso en Londres arreglando su plan a nuestras costumbres, o bien (que me parece lo mejor) adoptando el método antiguo de nuestras Cortes ${ }^{23}$.

Con respecto al poder del rey, hay que anotar que en 1811 algunos diputados conservadores abogaron por fijar determinadas atribuciones del monarca, como el nombramiento de altos cargos. Hubo quienes, como el religioso Jaime Creus y Martí, diputado por Cataluña, hablaron de «los males que podían resultar de que se concediese al rey la declaración de la guerra o la ratificación de la paz», que contemplaba el artículo 171.3 del proyecto constitucional24. Según el obispo de Calahorra, diputado por la Junta Superior de Burgos, no había duda de que Fernando VII era el titular de la soberanía. En su intento por fundamentar esta idea partió, entre otras premisas, de que «la potestad soberana es derivada de Dios a los reyes, mediante el pueblo en quien se dice residir primera y esencialmente», razonamiento éste en el que queda patente el influjo de las doctrinas neoescolásticas ${ }^{25}$. A su entender, la nación española había cedido irrevocablemente la soberanía «a su monarca elegido». En cualquier caso, el poder de los reyes no era ilimitado, pues éstos estaban obligados a observar «las condiciones y pactos que le están impuestos por [las] leyes fundamentales del reyno, y quando faltare a ellos tiene derecho la nación a exigir su cumplimiento, obligando al rey a la puntual observancia de la constitución por los medios que tenga prescritos la ley». Además, este pre-

21 ANÓNIMO (1809): pp. 6-8. Sobre lord Holland: MORENO ALONSO, 1997.

22 Carta del duque del Infantado a lord Holland (Sevilla, 10-12-1809), British Library (Kew-Londres), Holland Houses Papers, Add MS 51622, f. 76.

23 Dictamen del duque de Montemar sobre Cortes en mayo de 1814. Papel escrito en el mes de mayo de 1814 copiando otro que debió presentarse a la Junta Central el año de 1809, Archivo del Congreso de los Diputados (ACD), Papeles Reservados de Fernando VII. Papeles Sueltos. T XVI. Es probable que este dictamen fuera emitido por Montemar a petición de Fernando VII en calidad de presidente del Consejo de Indias, cargo que el aristócrata recibiera de manos del monarca a principios de julio de 1814.

24 La intervención de Jaime Creus en: DSCGE, 373 (10/10/1811): 2041.

25 DSCGE, 330 (28/08/1811): 1712-1713.VARELA SUANZES-CARPEGNA, 1983: 213. 
lado apelaba a una supuesta tradición para probar que los mandatos del rey, a quien califica de «legislador supremo», sólo eran legítimos cuando contaban con el consentimiento de las Cortes ${ }^{26}$. Algunos meses después, con motivo de la discusión del mencionado artículo 171, el diputado por Burgos Francisco Gutiérrez de la Huerta se dirigió a la cámara con las siguientes palabras: «¿Queremos conceder al rey un poder que sea infinito para hacer el bien? Creo que esto es lo que quiere el Congreso y yo soy el primero a convenir en ello; pero concédasele de modo que no lo pueda convertir en daño del Estado». A continuación, advertía: «Siempre y cuando se le den facultades absolutas para elegir a los que se le antoje para los destinos, es muy probable que su poder lo convierta en daño de la Nación ${ }^{27}$.

A propósito del artículo 1 del proyecto constitucional en el que se definía el concepto de nación, el diputado antiliberal Francisco de Salas Rodríguez de la Bárcena, quien formó parte de la Comisión de Constitución, observaba:

[...] he puesto mi firma al pie del proyecto que se ha presentado a la sanción de V.M. y del discurso preliminar que le precede; pero no por eso ha de creerse que todo el contenido de éste, y todos los artículos que comprende aquel, son conformes a mis ideas y que, por tanto, no puedo discurrir contra ellos $[\ldots]^{28}$.

Seguidamente, se refirió a «varios de mis compañeros, que también disienten» y aseguró que el proyecto contenía principios «contrarios a nuestro modo de pensar ${ }^{29}$. Los antiliberales habían sido minoría en la comisión que se encargó de la redacción del texto que se estaba debatiendo en las Cortes generales y extraordinarias, reunidas en septiembre del año anterior. Todos ellos refutaron la idea de nación entendida como unión de los ciudadanos (condición la de ciudadanía de la que, cabe recordar, fueron privados mujeres, trabajadores asalariados y esclavos) ${ }^{30}$. Para Rodríguez de la Bárcena, la nación era «un todo o compuesto moral, cuyas partes, por no tener un ser perfecto cada una de por sí en lo físico, no están dependientes ni unidas la una con la otra en la misma línea, y sólo un vínculo moral puede realizar esta unión política» ${ }^{31}$.

El proyecto constitucional recogía en su artículo 3 el principio de soberanía nacional proclamado por el primer decreto de las Cortes. El contenido de esta polémica disposición, que se discutió los días 28 y 29 de agosto, era el siguiente: «La soberanía reside esencialmente en la nación, y por lo mismo le pertenece exclusivamente el derecho de establecer sus leyes fundamentales y

26 DSCGE, 330 (28/08/1811): 1712-1713.

27 DSCGE, $378(15 / 10 / 1811): 2083$.

28 DSCGE, $378(15 / 10 / 1811): 6$ y 8.

29 DSCGE, 327 (26/08/1811): 1688.

30 CLAVERO, 10 (Madrid, 1987): 11-25. CASTELLS y FERNÁNDEZ, 2014: 99-123.

31 DSCGE, 378 (15/10/1811): 1688. 
de adoptar la forma de gobierno que más le convenga». Los diputados antiliberales cuestionaron todas las cláusulas apoyándose, entre otras razones, en que su aprobación implicaba atribuir a la nación una soberanía «sin limitación alguna», o sea, absoluta ${ }^{32}$. También hubo quienes, siguiendo la línea argumental del obispo de Orense y a Lardizábal, sostuvieron que este tipo de postulados eran los mismos que se habían defendido en la Francia de la Revolución, cuya imagen estaba ampliamente asociada en el imaginario popular de los españoles a las ideas de irreligión, guerra civil y caos desde $1793^{33}$. El diputado Joaquín Lorenzo Villanueva, preocupado por las afirmaciones que vertía la propaganda reaccionaria, se preguntó:

¿Qué ilustración adquirirán ahora los españoles menos instruidos con que les diga un escritor que estas Cortes extraordinarias no son las que el pueblo quería, sino un traslado de la Convención francesa? ${ }^{34}$

Algunos diputados antiliberales sugirieron que el rey era titular único de la soberanía, otros que la soberanía residía en las Cortes con el rey, idea ésta que posteriormente sería reformulada por el pensamiento liberal doctrinario ${ }^{35}$. Partiendo de estos asertos, formulados de forma ambigua, y del argumento de la ausencia del rey, hubo quienes infirieron que las Cortes generales y extraordinarias no estaban legitimadas para elaborar nuevas leyes. Llamas se pronunció en términos muy parecidos a los que lo hiciera el obispo de Orense en octubre del año anterior: «me parece más seguro y racional-concluye este diputado- que este augusto Congreso se limite a corregir y contener los abusos que ha introducido la arbitrariedad de los ministros y a restablecer y afirmar las antiguas leyes de la nación que fijaban los límites entre el trono y el pueblo» ${ }^{36}$. Lera, por su parte, también se expresó con rotundidad en este pun-

32 Consúltese la intervención de Borrull. DSCGE, 330 (28/8/1811): 1710.

33 AYMES, 1991: 438.

34 DSCGE, 381 (18/10/1811): 2104.

35 Llamas y Lera sugirieron que la soberanía reside en las Cortes con el rey. DSCGE, 324 (25/08/1811): 1687. DSCGE, 331 (29-8-1811): 1721 y ss. Algunos historiadores han señalado que los antiliberales manejaron (y confundieron) varias ideas de nación, entre las que nos limitaremos a referir las siguientes: 1. La nación como la reunión de los tres estamentos encabezados por el rey. 2. La nación como reino. 3. La nación como pueblo. 4. La nación como resultado de la unión del rey y reino. 4. La nación como agregado de distintos territorios. 5. La nación como la unión de las distintas clases sociales. Sobre las ideas de soberanía y nación utilizadas por los diputados antiliberales y sus influencias doctrinales: VARELA SUANZESCARPEGNA, 1983: esp. 210-219. PORTILLO VALDÉS, 2000.

36 DSCGE, 228 (28/08/1811): 1724. En una representación firmada en Cádiz el 3 de octubre de 1810, el obispo de Orense considera que «No es ahora tiempo de Constituciones, de leyes, de operaciones que piden un tiempo tranquilo y madurez de reflexiones y el sosiego de las pasiones, removido el fermento que las agita». Esta representación fue dada a la imprenta 
to: «Se equivoca, pues, quien diga que la nación, constituida como está, puede poner y hacer leyes, sin atender ni esperar el consentimiento del rey» ${ }^{37}$. Sometido el mencionado artículo 3 a votación, la primera parte del mismo en particular, que se correspondía con las dos primeras cláusulas (las relativas al reconocimiento de la soberanía nacional, definida en el artículo 1 como «la reunión de todos los españoles de ambos hemisferios»), fue aprobada por 128 votos contra $24^{38}$.

Desde un primer momento, los diputados antiliberales combatieron con acritud las ideas defendidas por la corriente ilustrada francesa más crítica, representada, entre otros pensadores, por Rousseau y Voltaire, a quienes señalaban como precursores de la Revolución francesa ${ }^{39}$. Ahora bien, no todos los ilustrados fueron demonizados. Ciertas ideas de Charles de Secondat, barón de Montesquieu (1689-1755), uno de los máximos exponentes de la Ilustración, fueron convenientemente instrumentalizadas en distintos momentos. Ya en 1810 Borrull había sostenido que la vieja Constitución del reino de Valencia, considerada como obligado referente para los legisladores contemporáneos, descansaba sobre los principios de división y equilibrio de los «tres poderes» del Estado («legislativo», «executivo» y «judicial»), el mejor de los baluartes frente al despotismo ${ }^{40}$. Pues bien, el 29 de diciembre de 1811 Alonso de la Vera y Pantoja, diputado por la ciudad de Mérida, presentó ante las Cortes una exposición en la que, apelando al «equilibrio de los poderes», proponía la disolución inmediata de la cámara y la convocatoria de elecciones para Cortes ordinarias. Este diputado aseguraba que las Cortes generales y extraordinarias se habían arrogado las tres potestades,

[...] rompiendo el legislativo la cadena de separación y respectiva independencia que todos tres deben poseer y conservar para mantener la independencia política de la Nación y la libertad civil el ciudadano, a cuya destrucción ha de suceder inevitablemente la anarquía o el despotismo.

Alonso de la Vera propugnaba la formación de una Regencia de cinco individuos, presidida por una persona real, con el «ejercicio pleno de las atribu-

por Manuel de LARDIZÁBAL y, años después, publicado por su autor en su polémico Manifiesto a la nación (1813). LASARTE, 2009: 105-210.

37 DSCGE, 331 (29/08/1811): 1722.

38 En su número de 30 de agosto de 1811, El Conciso (Cádiz) publicó una relación nominal de los diputados que votaron en contra de la primera parte en que fue dividido el artículo 3 del proyecto constitucional, aprobado en la sesión del día anterior. Sobre los papeles periódicos como fuente complementaria de los Diarios de Cortes: DURÁN LÓPEZ, 2008, vol. 2: 37-285.

39 Muchos de sus argumentos están presentes en la obra de los autores antiilustrados. EGIDO, 8 (1988): 121-142. HERRERO, 1994.

40 BORRULL Y VILANOVA, 1810. Sobre los postulados doctrinales de este diputado: TOMÁS Y VALIENTE, 65 (1995): 25, 49-50. 
ciones asignadas al rey en la Constitución» ${ }^{41}$. Aparentemente ajeno a estas palabras, un día después el liberal Francisco Fernández Golfín, diputado por Extremadura, se preguntaba:

Si las Cortes son perjudiciales; si los diputados abusan de sus poderes; si la nación desaprueba sus deliberaciones, ¿por qué no claman abiertamente contra ellas? Lardizábal lo hizo. ¿Y cuántos prosélitos ha hecho? Si lo que quieren es conforme al voto de todos los buenos españoles, ¿por qué ocultar su verdadero nombre el autor de La España vindicada? ¿Por qué no sabemos quiénes son los redactores de El Censor General y del Diario de la Tarde? ¿Diremos que se ocultan por modestia? ${ }^{42}$

Pocos meses más tarde, varios diputados realistas intentaron eludir la firma y jura de la Constitución política. Se trataba del diputado por Extremadura Pedro González Llamas, el diputado por el señorío de Vizcaya Francisco de Eguía, el diputado por Nueva Granada conde de Puñonrostro, el de Guadalajara José María Veladíez y Herrera y el diputado por Murcia Simón López ${ }^{43}$. Acto seguido, García Herreros instó a las Cortes a que acordaran que «cualquiera individuo del Congreso que se niegue a firmar la Constitución política de la Monarquía española y jurar lisa y llanamente guardarla, sea tenido por indigno del nombre español, privado de todos los honores, distinciones prerrogativas, empleos y sueldos y expelido de los dominios de España en el término de veinticuatro horas». Esta proposición quedó aprobada, y surtió los efectos deseados. Al menos momentáneamente. Los individuos mencionados accedieron a jurar la Constitución. Días después, el marqués de Villafranca protestó contra la prohibición de que los diputados expresaran objeciones al juramento ${ }^{44}$. Los rumores sobre la existencia de una conspiración contra las Cortes, que no siempre fueron infundados, se hicieron cada vez más insistentes ${ }^{45}$. Casi un año después, Argüelles afirmó que en la sesión de 8 de marzo de 1813 se descubrió la existencia de una «liga llamada de religión que, so

41 Por estos años, algunos diputados abogaron por que la presidencia de la Regencia se confiara a la infanta Carlota Joaquina. RIEU-MILLÁN, 1990: 361-363. RODRÍGUEZ LÓPEZ-BREA, 2002: 223-249.

42 DSCGE, 453 (30/12/1811): 2500. José Colón de Larreategui, quien fuera decano del Consejo de Castilla, reconoció la autoría de la España vindicada en sus clases y autoridades de las falsas opiniones que se la atribuyen. El autor reimprimió esta obra tras el regreso de Fernando VII: Madrid, Imprenta de Repullés, 1814.

43 Actas de las sesiones secretas de las Cortes generales extraordinarias... (en adelante, ASS) $(17 / 3 / 1812): 597$.

$44 \operatorname{ASS}(20 / 3 / 1812): 598$.

45 En 1810 se barajó la hipótesis de una trama conspirativa contra las Cortes en la que estarían implicados el obispo de Orense, el ex regente Lardizábal y una parte de los miembros del Consejo de Castilla. DSCGE, 579 (1/6/1812): 3239 y ss. 
color de que ésta peligraba, se extendía a varios puntos de la monarquía en secreto, desde Cádiz, asiento principal de esta facción [...] $\rangle^{46}$.

En las sesiones de Cortes no tardaron en salir a relucir las vinculaciones entre algunos diputados y los grupos sociales opuestos a la Constitución, entre los que sobresalían numerosos clérigos y aristócratas. En el acta secreta de 13 de junio de 1812 se informó de que el secretario de Gracia y Justicia había comunicado en un oficio firmado tres días antes que el juez del crimen de Cádiz había concluido que de «los números 116 y 118 del Diario de la Tarde y Censor General, número 31, calificados por la Junta Provincial de Censura de sediciosos y de infamatorios, resulta responsable el presbítero don Francisco Molle, quien dice ser editor de dicho periódico en concurrencia del señor diputado don Blas Ostolaza y marqués de Villapanés», y que «en unión con dichos señores es autor del anuncio de la carta del Filósofo Rancio en el Diario 118 y en El Censor; pero que del artículo denunciado en el Diario número 116 y en El Censor número 31 y de los del mismo papel titulado Censura del Diccionario Crítico-Burlesco y del Redactor general es autor el dicho don Blas Ostolaza» ${ }^{47}$.

Durante la guerra los contrarrevolucionarios ampliaron rápidamente su capacidad de influencia social. El argumento de la defensa del catolicismo del «pueblo español»y del rey fue esgrimido eficazmente para ampliar las bases sociales $^{48}$. El 4 de junio de 1812 la Comisión de Constitución votó la incompatibilidad del Tribunal de la Inquisición con la Constitución política de la monarquía. Borrull abogó por el mantenimiento de dicho tribunal ${ }^{49}$. Semanas después, su intervención en las Cortes fue difundida por El Procurador general de la nación y del rey, publicación reaccionaria ${ }^{50}$. El decreto de abolición de la Inquisición fue dado el 22 de febrero de 1813, tras uno de los más importantes debates de aquella legislatura ${ }^{51}$. El parecer de Llaneras, partidario de «la permanencia del tribunal de la Inquisición baxo las reformas que se

46 DSCGE, 849 (11/5/1813): 5205.

47 ASS (13/6/1812): 656. El Censor General y el Diario de la Tarde fueron dos conocidos diarios reaccionarios publicados en Cádiz. El dominico Francisco Alvarado es autor de $E l$ Filósofo Rancio, publicación en la que se realiza un alegato en favor de los intereses del clero y en contra de las ideas ilustradas. Por su parte, Bartolomé José Gallardo es autor del Diccionario crítico burlesco, obra que contiene críticas de marcado carácter anticlerical. Véase: SÁNCHEZ HITA, 9 (2012). Sobre la prensa antiliberal en el Cádiz de las Cortes: BUTRÓN PRIDA, 2010: 227-248. GIL NOVALES, 1994: 119-135.

48 ARIAS GONZÁLEZ y LUIS MARTÍN, 183 (1993): 231-235.

49 DSCGE, (19/1/1813): 4378 y ss.

50 Apéndice al Procurador General: Discurso de D. Francisco Javier Borrull y Vilanova, diputado por el reino de Valencia, sobre que el Tribunal de la Inquisición no es incompatible con la Constitución. El Procurador general de la nación y del rey, 17 de febrero de 1813.

51 LA PARRA y CASADO, 2013: 99-131. MORÁN ORTÍ, 1994. Habría que recordar que la proposición relativa a la incompatibilidad de la Inquisición con la Constitución de 1812 fue aprobada con 90 votos a favor y 60 en contra en la sesión de 22 de enero de 1813. 
considerasen necesarias en los procedimientos civiles, conformes a la Constitución política [...]», fue pronunciado en la sesión de 25 de ese mes, siendo aireado por la prensa reaccionaria ${ }^{52}$.

\section{EL CONFLICTO ENTRE LAS CORTES Y LA TERCERA REGENCIA}

En la sesión secreta de 21 de enero de 1812 las Cortes, controladas por los liberales, eligieron como regentes del reino, tras la realización de varios escrutinios, al duque del Infantado, Joaquín de Mosquera, Juan Villavicencio, Ignacio Rodríguez de Rivas y al conde de La Bisbal, hombres reputados por su conservadurismo. Pocos meses después, las tensiones entre liberales y contrarrevolucionarios se agudizaron considerablemente. Aparte de un conflicto competencial entre las Cortes y la tercera Regencia ${ }^{53}$, se constata un enfrentamiento político de mayor calado, provocado por el propósito de los regentes de bloquear la aplicación de las disposiciones acordadas por aquéllas, cediendo a las presiones del sector antiliberal más inmovilista. El detonante del cese de los cinco regentes por parte de la cámara, que se produjo el 8 de marzo de 1813, fue la no ejecución del decreto de abolición del tribunal de la Inquisición. En aquellas circunstancias, a la cabeza de los grupos reaccionarios se situaron el vicario capitular de la diócesis de Cádiz, algunos sacerdotes y el cabildo de la iglesia de la misma ciudad. En su correspondencia privada con determinadas personas del mundo diplomático, el duque del Infantado se presentó como protector de las luces. En una carta a lord Holland de principios de abril de 1813, este aristócrata aseguraba que la tercera Regencia no había obstaculizado la abolición de la Inquisición y que la inaplicación del decreto de las Cortes había estado motivada estrictamente por el intento de evitar desórdenes públicos ${ }^{54}$. No obstante, las afirmaciones del duque del Infantado no son concluyentes: so pretexto de observar las formalidades legales y velar por el orden, la Regencia dificultó a menudo la aplicación de la obra legislativa de las Cortes.

Algunas reformas fueron respaldadas por miembros de la Asamblea alejados del liberalismo, como ocurrió con el decreto de abolición de las jurisdicciones señoriales de 6 de agosto de 1811, que perseguía la ampliación del

52 Reproducción de la «Contestación del diputado en Cortes don Antonio Llaneras a la nota que el señor don Joaquín Lorenzo Villanueva, diputado por Valencia, pone contra él en su dictamen impreso página 44 con relación a lo que dixo Llaneras en el suyo en la sesión del 25 de enero de este año 1813». Semanario cristiano-político de Mallorca, 29 de abril de 1813.

53 FLAQUER MONTEQUí, 1/1 (Madrid, 1991): 37-65. FERNÁNDEZ SARASOLA, 2001.

54 Carta del duque del Infantado a lord Holland, Puerto de Santa María, 6-4-1813. BL, Holland Houses Papers, Add. Mss. 51622, ff. 87 y ss. 
ámbito jurisdiccional del Estado, objetivo largamente perseguido por la Corona española. Dentro y fuera de las Cortes, Ostolaza combatió enérgicamente la controvertida propuesta de García Herreros; no así el abogado Pedro Aparici y Ortiz, diputado suplente por Valencia y nada sospechoso de liberalismo, quien, entre 1811 y 1813 , se pronunció a favor de la abolición de señoríos jurisdiccionales y territoriales ${ }^{55}$. Este diputado dio a la imprenta la $\mathrm{Me}$ moria presentada a las Cortes en 1813, un papel que, con la aquiescencia de la Corona, sería citado ante los tribunales reales durante el Sexenio absolutista, al tiempo que los argumentos en él contenidos eran rebatidos por los aristócratas que habían apoyado el golpe de Estado en mayo de 181456. Entre ellos estaba el duque del Infantado ${ }^{57}$.

A mediados de septiembre de 1812 se leyó en las Cortes un dictamen en que se afirmaba que «la Regencia no duda que por el decreto de 11 de agosto deben cesar los jueces, regidores, escribanos y contadores titulares [...]; pero encuentra alguna dificultad en cuanto a los demás empleados municipales, aunque no se atreve a formar juicio sobre ello [...] $\rangle^{58}$. El teniente general duque del Infantado, que por entonces asumía la presidencia de la Regencia, era uno de los titulares de señoríos más importante de España. Durante la primera legislatura de las Cortes de Cádiz este noble, que fuera consejero de Fernando VII, presidente del extinto Consejo de Castilla y embajador de las Cortes en Gran Bretaña, firmó junto a numerosos grandes de España, títulos del reino y nobles de rango inferior varios escritos en contra de la abolición de los señoríos ${ }^{59}$. Hay que añadir que, como él, muchas de las personas que entre marzo de 1813 y mayo del año siguiente se aproximaron a las posiciones antiliberales habían defendido antes de la Guerra de la Independencia que las antiguas leyes fundamentales autorizaban al monarca para enajenar los bienes pertenecientes al Real Patrimonio en beneficio de la antigua grandeza del reino ${ }^{60}$.

55 Consúltese sus intervenciones en las Cortes: DSCGE (1/4/1813). Pedro Aparici y Ortiz era relator en lo civil de la Real Audiencia de Valencia (Guía política de las Españas para el año de 1812, Oficina de la Viuda de Comes, Cádiz, p. 32). A la altura de 1828, formaba parte del Colegio de Abogados (Guía de naturales y forasteros en Valencia y su estado militar, con un plano topográfico de esta ciudad, Valencia, Imprenta de D. Benito Monfort, 1828, p. 60). ARDIT LUCAS, 6 (Salamanca, 2007): 371-379. RAMÍREZ ALEDÓN, 2015: 78-104.

56 APARICI, 1813.

57 Carta de don Vicente Alonso al duque del Infantado que acompañaba a la impugnación de la Memoria de don Pedro Aparici (Valencia, 18 de marzo de 1815), BNE, Mss/11261/10.

58 DSCGE, 660 (19/09/1812): 3720.

59 HERNÁNDEZ MONTALBÁN, 1999: 39. Sobre la abolición de los señoríos en la monarquía hispánica, véase también: RUIZ RORRES, 1999, vol. I: 331-347.

60 Sobre el deslinde de los bienes del Estado de los del Real Patrimonio: GARCÍA MONERRIS, 2015: esp. 15-63. 
La tercera Regencia favoreció el nombramiento de personas no afines al sistema constitucional para el desempeño de cargos políticos, judiciales y militares. El diputado por Asturias y presidente de las Cortes Francisco Calello denunció que «La Constitución, obra tan grande como la grandeza de V.M., no se ha jurado por muchos, ya ciudadanos, ya empleados». Y añadió que «hasta las elecciones de diputados para las futuras Cortes han recaído en sujetos de los que algunos no la han jurado [...]» $\rangle^{61}$. Según se apunta en algún estudio, la designación de autoridades tuvo importantísimas consecuencias, por cuanto éstas influyeron en la elección de los nuevos diputados de Cortes $^{62}$. Por otra parte, fueron origen de desavenencias entre las Cortes y la Regencia la reorganización de los ejércitos, las órdenes de la Regencia expedidas entre el 25 de diciembre de 1812 y el 29 de enero de 1813 relativas al restablecimiento de las comunidades eclesiásticas y algunos sonados fracasos militares.

Fue Argüelles quien, apoyado por otros diputados, abogó por el cese de la tercera Regencia y el nombramiento de otra provisional. Su proposición quedó aprobada por 87 votos contra 4863. El cardenal Luis de Borbón, Pedro de Agar y Gabriel Císcar fueron investidos regentes. En aquella acalorada sesión, Zumalacárregui, Terán, Calatrava, conde de Toreno y Golfín, entre otros, profirieron comentarios negativos sobre la labor de los regentes salientes. Muy distinta fue la valoración que hicieron Ostolaza, Ocaña, Villagómez y el conde de Buenavista.

El aumento de las tensiones políticas y sociales entre liberales y reaccionarios queda patente en las felicitaciones elevadas a las Cortes por autoridades y corporaciones de distintos puntos del territorio español con motivo del cese de la tercera Regencia ${ }^{64}$. Liberales y contrarrevolucionarios se caracterizaron recíprocamente como «enemigos domésticos». Definitivamente, los josefinos ya no eran los únicos enemigos a combatir.

61 DSCGE, 826 (17/04/1813): 5067.

62 CHAVARRI SIDERA, 1988.

63 Reproducimos la proposición íntegra de Argüelles, realizada el 8 de marzo de 1813: «Que en atención a las circunstancias en que se halla la Nación, se sirva el Congreso resolver que se encarguen provisionalmente de la Regencia del reino el número de individuos del Consejo de Estado de que habla la Constitución en el artículo 189, agregándoles, en lugar de los individuos de la diputación permanente, dos individuos del Congreso, y que la elección de éstos sea en público y nominal». Puesta a votación la primera, hasta las palabras «la Constitución, artículo 189 inclusive», quedó aprobada por 87 votos contra 48. La segunda, hasta las palabras «del Congreso», se aprobó por 72 votos contra 66. La tercera no se sujetó a votación.

64 ACD, Serie General, leg. 30, exp. 3. 


\section{VOCES A FAVOR DEL REY ABSOLUTO}

Los antiliberales movieron adecuadamente sus redes de influencia y obtuvieron una amplia representación en las elecciones a Cortes ordinarias que habían sido convocadas en mayo de 1812. Se estima que los liberales sólo consiguieron un tercio de los escaños. En los Diarios de Cortes hay abundantes referencias a prácticas fraudulentas en los procedimientos electivos, pero no contamos con estudios sobre el particular. Entre la fecha en que se inició la primera legislatura ordinaria (1 de octubre de 1813) y la del cierre violento de las Cortes en mayo del año siguiente, se advierte la paralización de gran parte de la labor legislativa. Cabe destacar, sin embargo, que se adoptaron ciertas providencias encaminadas a aplicar el decreto sobre el establecimiento de la contribución directa, muy criticado por las jerarquías nobiliaria y eclesiástica ${ }^{65}$.

El 15 de enero de 1814 las Cortes ordinarias, que iniciaran su andadura en Cádiz, reanudaron sus sesiones en Madrid. Por entonces, cuatro de los individuos que compusieron la tercera Regencia (el duque del Infantado, Joaquín de Mosquera y Figueroa, Juan Villavicencio e Ignacio Rodríguez de Rivas) elevaron una representación a las Cortes, que fue dada a la imprenta, en la que afirmaban que su destitución había sido motivada por la tendencia irrefrenable de las Cortes liberales a detentar «una autoridad absoluta» e «indefinida». Estos individuos, desde posiciones inequívocamente reaccionarias, cuestionaban la legalidad del régimen político vigente, si bien se cuidaban de atacar directamente a la «nueva Constitución», la cual se jactaban de haber puesto en práctica «en medio de los embarazos que produce siempre el trastorno de las antiguas instituciones» ${ }^{66}$. Ante la incertidumbre política, se imponía sobre ellos la prudencia.

En 11 de diciembre de 1813 el conde de La Forest y el duque de San Carlos, en nombre Napoleón y Fernando VII, habían firmado el Tratado de Valençay. El duque de San Carlos se trasladó a Madrid con el principal objetivo de conseguir su ratificación, propósito que finalmente se vio frustrado: la Regencia, presidida por el cardenal de Borbón, y las Cortes, convinieron en re-

65 Oficio de remisión de 30 ejemplares de la orden circular de 16 de febrero de 1814 junto con el Decreto de las Cortes de 8 de febrero de 1814 donde se manda que los pueblos cesen las rentas provinciales después de acreditar tener anticipado el tercio que les corresponda por contribución directa, AHN, Consejos, 13563, exp.3, n. 4. En la prensa liberal encontramos numerosas alusiones al malestar que el establecimiento de la contribución directa provocó entre amplios sectores de la nobleza y el clero. Consúltese, por ejemplo: El Conciso (Madrid), 10 de marzo de 1814, pp. 427-428.

66 TOLEDO Y SALM-SALM et alii, 1814: 7, 11. El manuscrito original en: ACD, Serie General, leg. 8, doc. 36. Ni Villamil ni La Bisbal, afines a las posiciones antiliberales, suscribieron este papel. 
chazar dicho acuerdo con arreglo al decreto de 2 de febrero de 1814, según el cual «no se reconocerá libre al rey, ni por tanto se le prestará obediencia, hasta que en el seno del Congreso Nacional preste el juramento prescrito en el artículo 173 de la Constitución ${ }^{67}$. Hubo voces que comenzaron a cuestionar abiertamente los términos en que se formuló la respuesta dada por las autoridades a las condiciones de paz negociadas por Napoleón y Fernando, las cuales fueron consideradas como una mera imposición del primero. Así, en la sesión de 4 de febrero, el diputado por Sevilla López de Reina defendió que el «señor don Fernando VII nació con derecho a la absoluta soberanía y era «indispensable que siga ejerciendo la soberanía absoluta desde el momento que entre en la raya» ${ }^{68}$. Pocos días más tarde, el diputado por Cataluña José Antonio Navás, amparándose en el artículo 4 de la Constitución de 1812, trató de evitar la firma de las medidas que habían de adoptarse con motivo del regreso a España de Fernando VII, entre las que se encontraba la siguiente: «en cuanto llegue el rey a la capital vendrá en derechura al Congreso a prestar dicho juramento» ${ }^{69}$. Varias publicaciones periódicas liberales, como El Conciso, no tardaron en hablar de la existencia de un plan, urdido por Napoleón en conjunción con los «anticonstitucionales» españoles, para restablecer el régimen absolutista, dando crédito a los crecientes rumores de que Fernando era el instrumento de que pretendía valerse el emperador para recuperar su control político sobre España ${ }^{70}$.

La segunda legislatura dio comienzo el 25 de febrero del mismo año. A principios de marzo, las Cortes fueron informadas por la Regencia del avance

67 La minuta del decreto fue aprobada en la sesión secreta de 2 de febrero de 1814. Expediente relativo a las medidas adoptadas para preparar el regreso de Fernando VII, Archivo Histórico Nacional, en adelante AHN, Estado, 3566, exp. 64, f. 23. En el acta de la citada sesión se incluye una propuesta del diputado González Rodríguez en la que se alude a que dicho decreto fue aprobado por unanimidad de la cámara.

68 Actas de las sesiones de la legislatura ordinaria de 1814... (en adelante, AS), 91 (04/02/1814): 420. En medio del revuelo ocasionado por estas palabras, Cepero propuso que el Tribunal de Cortes formara contra López de Reina una causa judicial, que finalmente no prosperó. Según se lee en las Actas de Sesiones de las Cortes, este diputado logró huir de Madrid tras su expulsión de cámara. $A S, 99$ (12/02/1814): 459.

69 Oficio de José Antonio Navas a los secretarios de las Cortes, Madrid, 6-2-1814. Tres ejemplares de la orden de las Cortes Generales y Ordinarias por la que se dispone que los secretarios-diputados firmen el acta de la sesión secreta de 2 de Febrero, en la que se acordó el Decreto de 2 de Febrero de 1814 sobre las medidas a adoptar ante el regreso de Fernando VII a España, AHN, Estado, 3566, exp.65, f. 9-10.

70 El Conciso (Madrid), 11 y 26 de marzo de 1814. Anticipándose a las disposiciones de la Regencia y las Cortes, este periódico publicó, entre otros documentos, el Tratado de Valençay y varias cartas de Fernando VII dirigidas a la Regencia. Véase, por ejemplo, el número de 3 de febrero de 1814. Expediente relativo a las medidas adoptadas para preparar el regreso de Fernando VII..., esp. f. 82-133. 
de Fernando VII hacia la frontera española. El rey, que según el profesor Emilio La Parra había partido de Valençay el 13 de marzo con la idea formada de no mantener el sistema constitucional, entró en territorio español el 24 de ese mes ${ }^{71}$. Napoleón renunció al trono el 6 de abril en Fontainebleau, el mismo día que Luis XVIII fue reconocido como rey de los franceses. Oficialmente, los diputados españoles se hicieron eco de estas noticias casi dos semanas después 72 .

En un documento de 30 de abril que se insertó en las Actas de Cortes, los diputados antiliberales suplicaron a Fernando VII por segunda vez que apresurara su regreso a la capital. A su juicio, esta petición estaba motivada por «el antiguo desconcierto, el trastorno producido por seis años de la guerra más encarnizada y la divergencia de opiniones que ocasionan las mudanzas en los Estados», en clara referencia a las medidas impulsadas por los liberales en los años anteriores. Al pie de esta exposición, figuraban los nombres de Antonio Joaquín Pérez, Blas Ostolaza, Juan José Sánchez de la Torre, Tadeo Gárate y Tadeo Ignacio Gil ${ }^{73}$. Por aquellos días, aumentaron las dudas sobre la disposición favorable de Fernando a jurar la Constitución ${ }^{74}$.

El 10 de mayo de 1814 el general Elío marchó desde Ocaña a Aranjuez con tres mil hombres. La noche de ese día, Francisco Ramón de Eguía, quien había sido diputado suplente por el señorío de Vizcaya en las Cortes generales y extraordinarias, ejecutó la orden de arresto de los diputados liberales en calidad de capital general de Castilla La Nueva, cargo que recibiera de manos de Fernando VII en Valencia el 4 de mayo, la misma fecha en que se redactó el «Manifiesto» por el que el monarca, como soberano absoluto, suprimió el régimen constitucional ${ }^{75}$. Estos acontecimientos revelaron la existencia de una conspiración política de gran envergadura, instigada personalmente por Fernando VII con el respaldo, entre otros sectores sociales, de una parte del ejército, la Iglesia y la aristocracia. Conocemos mal las fechas y lugares en que se gestó dicha trama y las personas que colaboraron en su ejecución. Sería interesante esclarecer si algunos diputados antiliberales estaban al corriente de la misma. Algo mejor estudiada está la represión política ejercida sobre

71 LA PARRA LÓPEZ, 2012: 190.

$72 A S(21 / 04 / 1814): 284$.

73 ACD, Papeles Reservados de Fernando VII, T.72, ff. 64-67.

74 De nuevo, la prensa liberal no arremetió contra la persona de Fernando (su persona había sido declarada sagrada e inviolable por la propia Constitución), sino contra su entorno inmediato, integrado por personas de signo antiliberal, quienes habrían persuadido al rey de que el sentir general de los españoles era contrario a la Constitución de 1812. El Conciso (Madrid), 27 de abril de 1814.

75 Copia literal de los informes pedidos a varios sujetos con fecha de 21 de mayo de 1814 para poder formar cargos a los diputados, presos desde el 10 del mismo mes. BNE, Mss. Micro/404. 
hombres y mujeres acusados de afrancesados y liberales ${ }^{76}$. Entre los cargos más graves que se imputaron a los segundos en los tribunales reales, estaba el de haber defendido la soberanía nacional, acto que las autoridades absolutistas interpretaron como atentatorio contra los legítimos derechos del rey. Prueba de ello son las Causas de Estado, custodiadas en la sección Consejos del Archivo Histórico Nacional, necesitadas de más investigaciones ${ }^{77}$.

En un despacho firmado en Madrid en 22 de julio de 1814, el marqués de Wellesley informó a Wellington de la reciente impresión de un manifiesto firmado por sesenta y nueve diputados en que éstos aconsejaban al rey "not to swear to the new Constitution"78. Se trata del llamado Manifiesto de los Persas. En este documento, fechado en Valencia en 12 de abril del mismo año, se decía que la soberanía absoluta de los reyes radicaba en la necesidad de «prescribir a los súbditos todo lo que mira al interés común y obligar a la obediencia a los que se niegan a ella». Los firmantes recordaban que el poder de los monarcas tenía por límites las antiguas leyes fundamentales y suplicaban la reunión de Cortes estamentales ${ }^{79}$. Pero el monarca, interesado en fortalecer su poder, rehusó una y otra vez dicha convocatoria (a la que él mismo se había comprometido), de manera que el expediente del Consejo de Castilla acabó paralizándose ${ }^{80}$.

Según se desprende de las consultas y súplicas elevadas al rey con posterioridad a mayo de 1814, los antiliberales españoles, al igual que los franceses, no compartieron las mismas ideas respecto de los términos en que habría de efectuarse la reposición del orden anterior a $1808^{81}$. Pero este es ya otro tema de estudio.

76 Entre la bibliografía existente, podrían citarse las obras de Juan Francisco FUENTES y GARÍ (2014) y LÓPEZ TÁBAR (2001).

77 La conducta política de los diputados a Cortes fue objeto de investigación por parte de las autoridades absolutistas. En cumplimiento de las reales órdenes de Fernando VII, los jueces comisionados a tal efecto requirieron, entre otros documentos, una «certificación auténtica de todos los diputados que han asistido a unas y a otras Cortes, especificando en ella los que lo han hecho como propietarios y los que han concurrido como suplentes, y se pondrá otra certificación literal de la fórmula de los poderes de unos y otros». Auto firmado por Ignacio Martínez de Villela, Antonio Alcalá Galiano y Francisco de Leiva, jueces comisionados de policía, Madrid 21 de mayo de 1814. Causa de Estado contra Joaquín Lorenzo Villanueva, AHN, Consejos, 6311, exp. 2, f. 10v-13r.

78 Marqués de Wellesley a Castlereagh, Madrid, 22 de julio de 1814, The National Archives, Kew, Londres, FO/72/160, f. 170r.

79 J.M.J., 1814. BNE, Usoz/7481.

80 ARTOLA, 2008: 422-426.

81 HALÉVI, 1 (Paris, 1991): 31 


\section{CONCLUSIONES}

La coalición antiliberal que acabó por imponerse al término de la Guerra de la Independencia es el resultado de la confluencia gradual de personas, grupos e instituciones que juzgaron amenazados sus convicciones e intereses por la revolución. Estas páginas tratan de los orígenes de dicha coalición y de sus conexiones en las Cortes de Cádiz. Las fuentes documentales manejadas traslucen la complejidad interna del movimiento contrarrevolucionario, aspecto éste que en nuestra opinión no ha merecido el suficiente tratamiento historiográfico. En relación con esto, se ha insistido en que los diputados antiliberales esgrimieron distintos postulados con motivo de la discusión de la propuesta de abolición de los señoríos. Por otra parte, se ha constatado que algunos de ellos se pronunciaron por entonces en contra de los intentos de fortalecimiento del poder de la Corona en tiempos de Carlos IV, admitiendo la existencia de ciertos límites del poder del rey. Sobre el peso del sector más antirreformista en las Cortes, se concluye que no fue siempre el mismo. Los votos emitidos a propósito de la declaración de la soberanía nacional, el cese de la tercera Regencia y la incompatibilidad de la Inquisición con la Constitución de 1812 abonarían este supuesto.

Apelando a la defensa de Fernando VII, la religión, el orden y el sentir general de los españoles, la coalición antiliberal adquirió una considerable influencia social. Sin embargo, conviene no perder de vista que la abolición del régimen constitucional se consiguió mediante la violencia. Varios indicios sugieren que el papel de Fernando VII, interesado en suprimir todos los mecanismos de control del poder de la Corona, fue decisivo para el triunfo del golpe de Estado de 1814. Serán necesarias nuevas investigaciones para profundizar en el conocimiento de la alianza del rey con los contrarrevolucionarios y la dimensión social del enfrentamiento político entre serviles y liberales, dos cuestiones claves para explicar la construcción del Estado liberal en España.

\section{FUENTES PRIMARIAS}

Anónimo (atribuido a lord Holland y John Allen), Insinuaciones sobre las Cortes, Londres, Blackader Printer, 1809.

Aparici y Ortiz, Pedro, Memoria que presentó a las Cortes generales y extraordinarias D. Pedro Aparici y Ortiz, diputado por la provincia de Valencia, y leyó en las sesiones de 31 de marzo y 1 de abril, mandada pasar a la comisión de señoríos, sobre que los dueños territoriales carecen de título legítimo para retener los raices que dexaron los moriscos al tiempo de ser expelidos de España; y quando le tuviesen, deben regularse los pagos de derechos enfitéuticos con que se concedieron dichos bienes, Valencia, Imprenta de D. Benito Monfort, 1813. 
Borrull y Vilanova, Francisco Xavier, Discurso sobre la Constitución que dio al reyno de Valencia su invicto conquistador el señor don Jayme Primero por Francisco Xavier Borrull y Villanova, juez de diezmos, primicias y tercios-diezmos de dicho reyno, [s.1.], 1810.

Cortes generales y extraordinarias, Diario de Sesiones de las Cortes generales y Extraordinarias (1810-1813), Madrid, 1870.

Cortes generales y extraordinarias, Actas de las sesiones secretas de las Cortes generales extraordinarias de la Nación española, que se instalaron en la Isla de León el día 24 de septiembre de 1810 y cerraron sus sesiones en Cádiz el 14 de igual mes de 1813. De las celebradas por la Diputación Permanente de Cortes, instalada en la propia ciudad el día 9 de dicho mes, y de las secretas de las Cortes ordinarias que se instalaron en la misma ciudad el 25 del propio mes, y trasladadas a Madrid fueron disueltas en su segunda legislatura el 10 de mayo de 1814, Madrid, 1874.

Cortes generales y extraordinarias, Actas de las sesiones de la legislatura ordinaria de 1814, Madrid, Viuda e Hijos de don Antonio García, 1876.

Duaso (Duazo) y Latre, José, Vicios de la contribución directa decretada por las Cortes extraordinarias en 13 de septiembre de 1813, Madrid, Imprenta de Ibarra, 1814.

Jovellanos, Gaspar Melchor de, «Consulta sobre la convocación de las Cortes por estamentos» (Sevilla, 21-5-1809), en D. Gaspar de Jovellanos a sus compatriotas. Memoria en que se rebaten las calumnias divulgadas contra los individuos de la Junta Central, La Coruña, Oficina de D. Francisco Cándido Pérez Prieto, 1811.

Joven, Josef Ignacio y Toledo y Salm-Salm, Pedro Alcántara de (Duque del Infantado), Por el duque del Infantado en el pleyto con los señores fiscales y la villa de Alberique sobre la incorporación de dicha villa a la real corona, Madrid, Imprenta de la Viuda de don Joaquín Ibarra, 1804.

J. M. J., Representación y manifiesto que algunos diputados a las Cortes ordinarias firmaron en los mayores apuros de su opresión en Madrid para que la Majestad del señor don Fernando VII a la entrada en España de vuelta de su cautividad se penetrase del estado de la nación, del deseo de sus provincias y del remedio que creían oportuno; todo fue presentado a S.M. en Valencia por uno de dichos diputados y se imprime en cumplimiento de dicha real orden, Madrid, Imprenta de Ibarra, 1814.

Lardizábal y Uribe, Miguel de, Manifiesto a la nación el consejero de Estado don Miguel de Lardizábal y Uribe, Alicante, Nicolás Carratalá, 1811.

Quevedo y Quintano (obispo de Orense), Manifiesto del obispo de Orense a la nación española, La Coruña, Oficina del Exacto Correo, 1813.

Reguera Valdelomar, Juan de la, Peticiones sobre reparo de agravios causados en el fatal reinado de Carlos IV dirigidas a la nación española reunida y representada en Cortes generales, Madrid, Oficina de Collado, 1810.

Salas, Tomás de, Cartas patrióticas. Carta segunda: España monarquía, precavida del despotismo. Dedicadas al Excelentísimo Señor duque del Infantado, Sevilla, Viuda de Vázquez y Compañía, 1809. 
Toledo y Salm-Salm, Pedro Alcántara de (duque del Infantado), Representación de los individuos que compusieron la Regencia constitucional y se expresan en ella, presentada a las Cortes por medio de su presidente el día 5 del corriente febrero, Madrid, Imprenta de Ibarra, 1814.

Villaverde, marqués de, ¿Qué era la Constitución?, o sea Observaciones sobre la que sancionaron las Cortes generales y extraordinarias publicadas en 1812, y reimpresas ahora de nuevo en un solo volumen por su autor don Benito María Sotelo de Naboa y Niño, marqués de Villaverde, \&, caballero maestrante de Ronda, vecino y regidor perpetuo que era de la ciudad de Orense, y como tal diputado por la misma provincia, e individuo de la primera y suprema Junta del Reyno de Galicia en 1808, Madrid, Imprenta de Ibarra, 1814.

\section{BiBLIOGRAFÍA}

Ardit Lucas, Manuel, «Política e historia en el debate sobre los señoríos de las Cortes de Cádiz», Studia historica. Historia Moderna, 6 (Salamanca, 1998): 371-379.

Arias González, Luis y Luis Martín, Francisco de, «La divulgación popular del antiliberalismo a través del sermón», Hispania, 183 (1993): 213-235.

Aróstegui, Julio, «La contrarrevolución española en el contexto de la contrarrevolución en Europa», en José Antonio Ferrer Benimeli (coord.), Masonería, revolución y reacción, Alicante, Instituto de Cultura Juan Gil-Albert, 1990; 573-594.

Artola Gallego, Miguel, La España de Fernando VII, Madrid, Espasa, 2008.

Aymes, Jean-René, La guerra de España contra la Revolución francesa (1793-1795), Alicante, Instituto de Cultura Juan Gil-Albert, 1991.

Baras Escolá, Fernando, El reformismo político de Jovellanos (nobleza y poder en la España del siglo XVIII), Zaragoza, Universidad de Zaragoza, 1993.

Butrón Prida, Gonzalo, «Ciudadanos católicos. Mitos e imágenes de la propaganda antiliberal en el Cádiz sitiado», en Emilio La Parra López (ed.), La Guerra de Napoleón en España. Reacciones, imágenes, consecuencias, Alicante, Casa de Velázquez-Universidad de Alicante, 2010; 227-248.

Butrón Prida, Gonzalo, «Redefinir rey y soberanía: el retorno de Fernando VII y la agonía del liberalismo», Pasado y Memoria. Revista de Historia Contemporánea, 13 (Alicante, 2014): 59-78.

Castells, Irene, y Fernández, Elena, «Las mujeres y el primer constitucionalismo español», en Irene Castells (coord.), Mujeres y constitucionalismo histórico español. Seis estudios, Oviedo, CEPC, 2014; 99-123.

Chavarri Sidera, Pilar, Las elecciones de diputados a las Cortes generales y extraordinarias (1810-1813), Madrid, CEPC, 1988.

Clavero, Bartolomé, «Cara oculta de la Constitución: sexo y trabajo», Revista de las Cortes Generales, 10 (Madrid, 1987): 11-25.

Coronas González, Santos M., «El pensamiento constitucional de Jovellanos», Historia Constitucional, 1 (2000): 63-96. Disponible en: http://hc.rediris.es/01/index.html 
Dedieu, Jean-Pierre, Après le roi. Essai sur l'effondrement de la monarchie espagnole, Madrid, Casa de Velázquez, 2005.

Durán López, Fernando, «Diputados de papel: la información parlamentaria en la prensa de la etapa constituyente (septiembre de 1810-marzo de 1812)», en Marieta Cantos Casenave, Fernando Durán López y Alberto Romero Ferrer (eds.), La guerra de pluma. Estudios sobre la prensa de Cádiz en el tiempo de las Cortes (1810-1814), Cádiz, Universidad de Cádiz, 2008; 37-285.

Egido, Teófanes, «Los antiilustrados españoles», Investigaciones históricas: época moderna y contemporánea, 8 (1988): 121-142.

Fernández Sebastián, Javier, «Liberales y liberalismo en España, 1810-1850. La forja de un concepto y la creación de una identidad política», Revista de Estudios Políticos (nueva época), 134 (Madrid, 2006): 125-176.

Fernández Sarasola, Ignacio, Poder y libertad: los orígenes de la responsabilidad del ejecutivo en España (1808-1823), Madrid, CEPC, 2001.

Flaquer Montequí, Rafael, «El ejecutivo en la revolución liberal», Ayer, 1 (1991): 37-65.

Friera Álvarez, Marta, «El realismo jovellanista de Alonso Cañedo», Historia Constitucional, 14 (2013): 1-43.

Fuentes, Juan Francisco y Garí, Pilar, Amazonas de la libertad: mujeres liberales contra Fernando VII, Madrid, Marcial Pons, 2014.

García Monerris, Carmen, La Corona contra la Historia. José Canga Argüelles y la reforma del Real Patrimonio Valenciano, València, Universitat de València, 2004.

García Monerris, Encarna, y García Monerris, Carmen, «Palabras en guerra. La experiencia revolucionaria y el lenguaje de la reacción», Pasado y Memoria. Revista de Historia Contemporánea, 10 (Alicante, 2011): 139-162.

García Monerris, Encarna, y García Monerris, Carmen, Las cosas del rey. Historia política de una desavenencia (1808-1874), Madrid, Akal, 2015.

Gil Novales, Alberto, «Las críticas al Diccionario crítico-burlesco en la prensa de la época», en Mélanges offerts à Albert Dérozier, Besançon-París, Annales Littéraires de l'Université de Besançon, 1994; 119-135.

Halévi, Ran, « La contre-révolution », Civilisations, 18 (Paris, 1990): 29-32.

Herrero, Javier, Los orígenes del pensamiento reaccionario español, Madrid, Alianza, 1994 ( $1^{\text {a }}$ ed. 1971).

Hernández Montalbán, Francisco J., La abolición de los señorios en España (18111837), Madrid, Biblioteca Nueva-Universidad de Valencia, 1999.

Hocquellet, Richard, «El complejo de huérfano. Los españoles antes de la acefalía», en Emilio La Parra López (ed.), La Guerra de Napoleón en España. Reacciones, imágenes, consecuencias, Alicante, Universidad de Alicante-Casa de Velázquez, 2010; 51-66.

La Parra López, Emilio, Manuel Godoy. La aventura del poder, Barcelona, Tusquets, 2005 (1 $1^{\mathrm{a}}$ ed. 2002).

La Parra López, Emilio, «El mito del rey deseado», en Christian Demange, Pierre Géal, Richard Hocquellet, Stéphane Michonneau y Marie Salgues (eds.), Som- 
bras de Mayo. Mitos y memorias de la Guerra de la Independencia (1808-1908), Madrid, Casa de Velázquez, 2007; 221-236.

La Parra López, Emilio, «Napoleón y el golpe de Estado de 1814 en España», en Xavier Huetz de Lemps y Jean-Philippe Luis (eds.), Sortir du labyrinthe. Études d'Histoire Contemporaine de l'Espagne. Hommage à Gérard Chastagnaret, Madrid, Casa de Velázquez, 2012; 171-191.

La Parra López, Emilio y Casado, María Ángeles, La Inquisición en España. Agonía y abolición, Madrid, Catarata, 2013.

Lasarte, Javier, Las Cortes de Cádiz. Soberanía, separación de poderes, Hacienda. 1810-1811, Madrid, Marcial Pons-Universidad Pablo de Olavide, 2011.

López Tábar, Juan, Los famosos traidores: los afrancesados durante la crisis del Antiguo Régimen (1808-1833), Madrid, Biblioteca Nueva, 2001.

Luis, Jean-Philippe, «La construcción inacabada de una cultura política realista», en Miguel Ángel Cabrera y Juan Pro (coords.), La creación de las culturas políticas modernas, 1808-1833, Madrid-Zaragoza, Marcial Pons-Prensas Universitarias de Zaragoza, 2014; 319-345.

Martin, Jean-Clément, Révolution et contre-révolution en France, 1789-1989. Les rouages de l'Histoire, Rennes, Presses Universitaires de Rennes, 1996.

Martínez Pérez, Fernando, Constitución en Cortes: el debate constituyente, 18111812, Madrid, UAM, 2011.

Morán Ortí, Manuel, Revolución y reforma religiosa en las Cortes de Cádiz, Madrid, Actas, 1994.

Moreno Alonso, Manuel, La forja del liberalismo en España: los amigos españoles de lord Holland, 1793-1840, Madrid, Congreso de los Diputados, 1997.

Olaechea, Rafael, El conde de Aranda y el "partido aragonés”, Zaragoza, Universidad de Zaragoza, 1969.

Portillo Valdés, José María, «¿Existía una Antigua Constitución española? El debate sobre el modelo inglés en España, 1808-1812?», en Andrea Romano (ed.), Il modello costituzionale inglese e la sua recezione nell'area mediterranea tra la fine del 700 e la prima metà dell'800, Milano, Giuffrè, 1998; 545-585.

Portillo Valdés, José María, Revolución de Nación. Orígenes de la cultura constitucional en España, 1780-1812, Madrid, CEPC-BOE, 2000.

Ramírez Aledón, Germán, «La presencia valenciana en las Cortes de Cádiz: nuevas aportaciones y viejas ausencias», en Manuel Chust (ed.), Valencianos en revolución, 1808-1821, València, Universitat de València, 2015; 78-104.

Rieu-Millán, Marie-Laure, Los diputados americanos en las Cortes de Cádiz: igualdad o independencia, Madrid, CSIC, 1990.

Rodríguez López-Brea, Carlos, Don Luis de Borbón, el cardenal de los liberales (1777-1823), Toledo, JJCM, 2002.

Rodríguez López-Brea, Carlos, «Don Pedro Inguanzo y Rivero, un canónigo antiilustrado en las Cortes de Cádiz», Historia Constitucional, 14 (2013): 77-91.

Roura, Lluis, «La Contre-Révolution en Espagne et la lutte contre la France, 17931795, et 1808-1814», en Jean-Clément Martin, La Contre-Révolution en Europe, 
$X V I I I^{e}-X I X^{e}$. Réalités politiques et sociales, résonances culturelles et idéologiques, Rennes, Presses Universitaires de Rennes, 2001; 205-220.

Ruiz Torres, Pedro, «Señorío y propiedad en la crisis del Antiguo Régimen», en Salustiano de Dios, Javier Infante, Ricardo Robledo y Eugenia Torijano (coords.), Historia de la propiedad en España. Siglos XV-XX. Encuentro Interdisciplinar. Salamanca, 3-6 de junio de 1998, Madrid, Centro de Estudios Registrales, [1999].

Rújula, Pedro, «Realismo y contrarrevolución en la Guerra de la Independencia», Ayer, 86/2 (Madrid, 2012): 45-66.

Rújula, Pedro, «El antiliberalismo reaccionario», en María Cruz y María Sierra (coords.), La España liberal, 1833-1874, Madrid-Zaragoza, Marcial PonsPrensas de la Universidad de Zaragoza, 2014; 377-410.

Sánchez Blanco, Francisco, El Absolutismo y las Luces en el reinado de Carlos III, Madrid, Marcial Pons, 2002.

Sánchez Hita, Beatriz, «Las empresas periodísticas del marqués de Villapanés: literatura y prensa absolutista en las Cortes de Cádiz», Argonauta español, 9 (2012). Disponible en: https://argonauta.revues.org/783.

Saint Victor, Jacques de, La première contre-révolution (1789-1791), París, PUF, 2010.

Tomás y Valiente, Francisco, «Génesis de la Constitución de 1812. De muchas leyes fundamentales a una sola Constitución», Anales de Historia del Derecho, 65 (1995): 13-126.

Varela Suanzes-Carpegna, Joaquín, La teoría del Estado en los orígenes del constitucionalismo hispánico (Las Cortes de Cádiz), Madrid, CEPC, 1983.

Recibido: 26/05/2016

Aprobado: 07/03/2017 